\title{
Incorporating Platelet Rich Plasma and Platelet Poor Plasma into Open Reduction Internal Fixation of Closed Calcaneus Fractures to Reduce Wound Complication: A Case Study
}

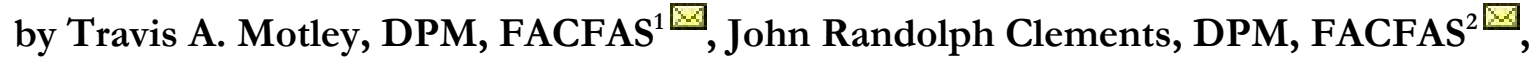 \\ J. Kalieb Pourciau, DPM ${ }^{3} \otimes$
}

The Foot and Ankle Online Journal 2 (11): 1

Background: Calcaneal fractures are high energy injuries. There is some debate with the advantages and disadvantages of treating calcaneal fractures with open reduction and internal fixation based on surgical complication rates.

Methods: We describe the management of 12 patients who presented to our emergency department with 14 closed intra-articular calcaneal fractures (7 Sanders Class III fractures, 7 Sanders class IV fractures). These 14 fractures were treated with open reduction and internal fixation. We describe a technique using platelet rich plasma and platelet poor plasma in the closing of the soft tissues after open reduction of calcaneal fractures.

Results: While complications with open reduction of calcaneal fractures include poor wound healing and infection and can range between 26 and 60 percent, we observed no complications in our small series.

Discussion: Wound complications are the most common and potentially threatening consequence of open reduction and internal fixation of calcaneal fractures. The purpose of this case study is to offer the addition of platelet rich plasma (PRP) and platelet poor plasma (PPP) in the treatment of these complicated injuries. The study also attributes the low complication rate to application of pre-operative bulky Jones type splinting, appropriate surgical timing, pre-operative intravenous antibiotic administration, extensile lateral subperiosteal approach and "hands off" retraction. As well as low profile hardware, drain placement, layered closure with Algower-Donati suture technique, surgeon experience and appropriate post-operative bulky splinting. Our series matched that of previous studies without a single wound complication.

Key Words: Trauma, calcaneal fractures, Algower-Donati suture technique, platelet rich plasma (PRP), platelet poor plasma (PPP).

Accepted: October, $2009 \quad$ Published: November, 2009

This is an Open Access article distributed under the terms of the Creative Commons Attribution License. It permits unrestricted use, distribution, and reproduction in any medium, provided the original work is properly cited. (The Foot and Ankle Online Journal (www.faoj.org)

Address correspondence to: Travis Motley, DPM, MS, FACFAS, John Peter Smith Hospital, 1500 South Main Street, Department of Orthopaedics, Fort Worth, TX 76104. tmotley@jpshealth.com

\footnotetext{
${ }^{1}$ Travis Motley, DPM, MS, FACFAS, John Peter Smith Hospital, 1500 South Main Street, Department of Orthopaedics, Fort Worth, TX 76104. tmotley@jpshealth.com

${ }^{2}$ J. R. Clements, DPM, FACFAS, The Carilion Clinic,Department of Orthopaedics, Three Riverside Place, Roanoke, VA 24014. jrclements@carilion.com

3 J. Kalieb Pourciau, DPM, Acadian Medical Center, 3521 Hwy 190 East, Suite U, Eunice, LA 70535. kpourciau@gmail.com
}

The calcaneus is the most commonly fractured tarsal bone constituting $60 \%$ of all major tarsal injuries, but only $2 \%$ of all fractures of the body. ${ }^{1}$ Calcaneus fractures are high energy injuries ${ }^{2}$ and most commonly occur with a fall from a height. ${ }^{1}$

A study by Lance, et al., ${ }^{3}$ has recorded calcaneal fractures from falls ranging three to fifty feet with an average of 14 feet. 
There is debate over the appropriate treatment for closed calcaneal fractures. The majority of this debate deals with complication rates and functional outcomes of conservative versus surgical management.

Complications of open reduction internal fixation (ORIF) include, but are not limited to, wound complications (dehiscence, hematoma, erythema, cellulitis, and infection), thromboembolism (deep venous thrombosis and pulmonary embolus), malreduction, compartment syndrome, nerve conditions (entrapment, numbness, reflex sympathetic dystrophy), osteomyelitis, and shoewear modifications. Subsequent operations may be required such as fasciotomy, secondary arthrodesis, peroneal nerve neurolysis, hardware removal, exostectomy, and irrigation and debridements for deep surgical site infections. ${ }^{4,5}$ Several predisposing factors contribute to wound complications. Furthermore, the Sanders classification ${ }^{6}$ can be predictive of complication rates. A previous study reported Sanders Class II calcaneal fractures have an overall complication rate of $27 \%$, Class III fractures are $26 \%$, and Class IV fractures are 60\%. ${ }^{4}$ The overall complication rate with ORIF of all closed calcaneal fractures is between $0 \%$ and $25 \%$ with wound complications being between $0 \%$ and $16 \%$.

Soft tissue and bone healing are mediated by a cascade of intra- and extracellular events. These events are regulated by signaling proteins and specific healing stages. Wound healing has three overlapping stages: inflammation, proliferation, and remodeling. Inflammation is the initial response to tissue injury. The main goal of the inflammatory phase is to provide rapid hemostasis and begin the sequence of events that leads to regeneration of tissue. During the proliferative phase, the damaged, necrotic tissue that is being removed via phagocytosis starts to be replaced with living tissue that is specific to the local tissue environment. During remodeling, the newly generated tissue reshapes and reorganizes to more closely resemble the original tissue. ${ }^{7}$
Platelets play a prominent role as one of the first responders during the acute inflammatory phase. In response to tissue damage, platelets are activated resulting in the formation of a platelet plug and blood clot for hemostasis. The alpha granules of activated platelets contain numerous proteins that influence wound healing. These include platelet derived growth factor, transforming growth factor, insulin-like growth factor, and Factor $\mathrm{V}$, among others. In the presence of calcium, Factor $\mathrm{V}$ binds to activated factor $\mathrm{X}$ to produce prothrombin activator which converts prothrombin to thrombin. Thrombin then converts fibrinogen to fibrin which binds to platelet surface receptors. This activates another series of factors which are involved in activating factor $\mathrm{X}$ via the intrinsic pathway. ${ }^{7}$ These proteins from platelet degranulation are partly responsible for cellular chemotaxis, proliferation, and differentiation. This includes removal of tissue debris, angiogenesis, establishing the extracellular matrix, and regeneration of the appropriate type of tissue.

Platelet rich plasma (PRP) is, by definition, a volume of the plasma fraction of autologous blood having a platelet concentration above baseline. ${ }^{8}$ Therefore, PRP has the full complement of clotting factors and higher concentration of platelets. The portion of plasma that remains deficient in platelets is known as platelet poor plasma (PPP). PPP has clinical roles as fibrin sealant for hemostasis. Platelet concentrations in PRP range from $2-8.5$ times that of normal plasma. $^{7}$

\section{Methods}

Each patient enrolled in our study was stabilized by one of the three authors in our emergency department. The optimal time for operation was determined by soft tissue indicators: absence of fracture blisters, positive skin wrinkle test, and restoration of elastic properties within the area of incision. Preoperatively, all patients received one gram of Cephalexin, or one gram of Vancomycin if patient had an allergy to penicillin, intravenously 30 minutes prior to the procedure. 


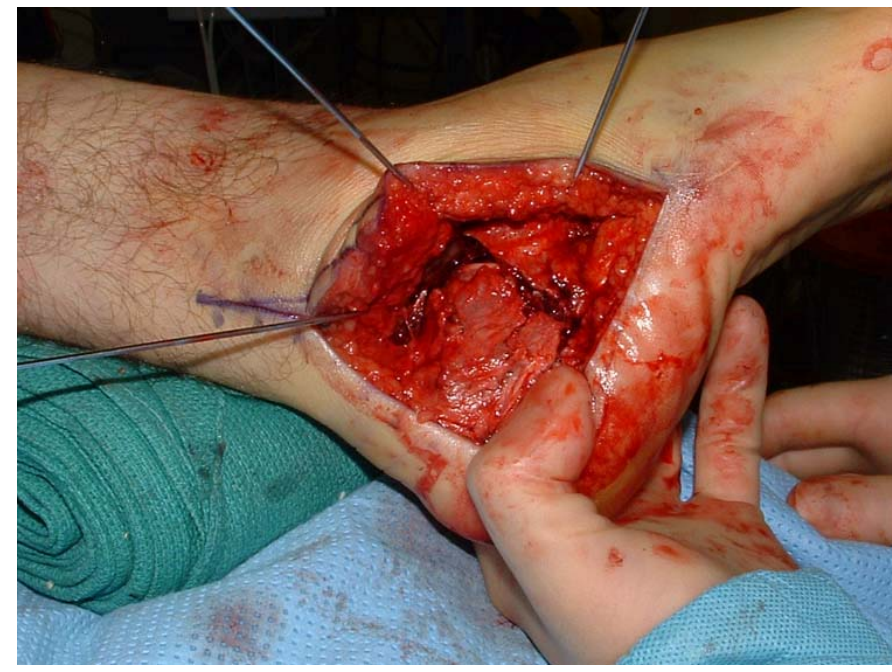

Figure 1 Extensile lateral approach with Kirschner wires retracting full-thickness skin flap.

Patients were placed in a lateral decubitus position depending on the operative side. A pneumatic thigh cuff was used for hemostasis. The operative foot was supported with a Seattle pillow. The operative leg was then prepped and draped using aseptic technique. The leg was elevated and exsanguinated and the tourniquet was then inflated. A surgical marking pen was then used to draw an L-shaped lateral extensile incision over the lateral aspect of the calcaneus as to maximally preserve the blood supply to the lateral subperiosteal flap as described by Borelli. ${ }^{9}$ The horizontal arm was $2 \mathrm{~cm}$ superior to the plantar fat pad, the vertical arm of this incision was $1 \mathrm{~cm}$ anterior to the Achilles tendon. Each arm of the " $L$ " measured approximately $8 \mathrm{~cm}$ in length. The incisions were initially made to the level of the bone. The subperiosteal flap, including the peroneal tendons and the sural nerve, was elevated from the lateral wall of the calcaneus superiorly and retracted with Kirschner wires in the fibula, talus, and cuboid. (Fig. 1) This allowed visualization of the lateral calcaneal body, the calcaneocubiod joint and the subtalar joint.

After reduction of the articular surfaces, calcaneal body and the lateral calcaneal wall, a low profile titanium perimeter plate and screws (ACE-Depuy, Warsaw, Indiana) was utilized for fixation.

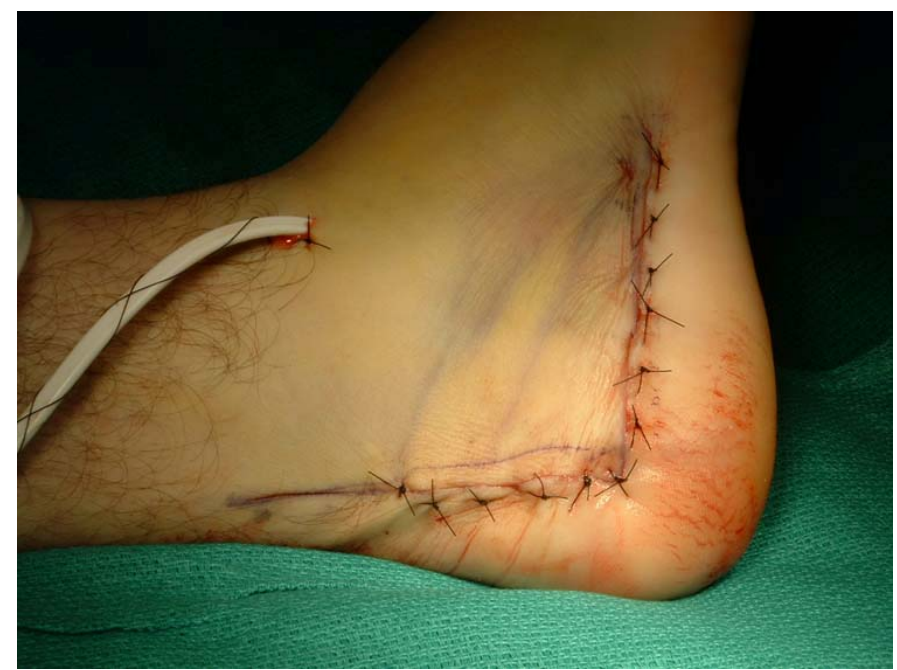

Figure 2 Closed extensile lateral approach with Allgower-Donati suture technique. Drain exit site is beyond region of the elevated flap.

The wound was copiously irrigated with normalized saline using bulb syringe. A 4-mm flat Jackson-Pratt facial drain was then placed exiting dorsally and sutured into place. Next, PRP derived from the Gravitational Platelet Separation System $\left(\right.$ GPS $^{\circledR}$ III, Biomet $^{\circledR}$, Inc., Warsaw, Indiana) was then applied to any body defects and the operative field. The wound was then carefully closed in layers using 2-0 Vicryl Ethicon $^{\circledR}$, Johnson \& Johnson, Inc., Somerville, New Jersey) for deep tissue, 3-0 Vicryl (Ethicon ${ }^{\circledR}$, Johnson \& Johnson, Inc., Somerville, New Jersey) subcutaneously, and 4-0 Ethilon (Ethicon ${ }^{\circledR}$, Johnson \& Johnson, Inc., Somerville, New Jersey) to reapproximate the skin using the horizontal Allgower - Donati suture technique. ${ }^{10}$ (Fig. 2) Platelet poor plasma from the GPS ${ }^{\circledR}$ III system was then applied above the incision. The wound was bandaged with sterile gauze, kling, and a bulky Curity ${ }^{\mathrm{TM}}$ Lakeside $^{\mathrm{TM}}$ cotton roll (The Kendall Company, Boston, Massachusetts) compressive posterior splint. The tourniquet was deflated and there were typical hyperemic responses to all the digits. Patients were admitted for postoperative pain management. Drain output was recorded until it produced $30 \mathrm{cc}$ or less in 24 hours. Then, the drain was removed. All patients received one gram of Cephalexin every eight hours or one gram of Vancomycin every 12 hours post operatively until discharged. 
Patients were discharged home when their pain was managed appropriately with oral medication. Utilizing this technique, none of our patients had wound complications. Each patient healed the surgical site without incident.

\section{Results}

We report on open treatment of 14 calcaneal fractures from 12 patients. Thirteen of the fourteen were sole ORIF of intra-articular calcaneal fractures. One of the fourteen had a primary subtalar joint arthrodesis in addition to reduction of the calcaneus. This patient was included in the study because the surgical approach and timing resembled the other patient who received ORIF. Eleven patients were male, one was female. One patient sustained bilateral injury, and received bilateral repair. Ten of our patients had no pertinent past medical history. One male had a past medical history of transient ischemic attacks, hypertension, and hypothyroidism. One female had a history of numerous psychiatric disorders. Fifty percent (6 of 12) of our patients had social histories significant for tobacco use. There were seven right and seven left calcaneal fractures. Average follow up time period was 11.4 months (range 7-18 months). Average patient age was 35.25 (range from 21 - 69). There were no wound complications in our series utilizing our technique.

\section{Discussion}

Calcaneal fractures are high energy injuries with reported complications after ORIF of $0-25 \% \%^{4,5}$ There is still debate regarding ORIF compared conservative treatment of closed calcaneal fractures based on these complications. In a prospective randomized trial comparing open reduction and internal fixation with non-operative treatment, Howard, et al., ${ }^{4}$ reported complication rates of $25 \%$ in ORIF of 226 intra-articular calcaneus fractures.

(C) The Foot and Ankle Online Journal, 2009
This was then subcategorized into $16 \%$ wound complications, $5.8 \%$ malpositions of fixation, $1.2 \%$ thromboembolisms, $1.6 \%$ compartment syndromes, and $0.4 \%$ deep infections. All surgeons used the lateral extensile approach in their study.

According to a literature review done by Benirschke and $\mathrm{Kramer}^{5}$, serious infections (those requiring more than oral antibiotic therapy) after ORIF of closed calcaneus fractures range from $0 \%$ to $20 \%$. They site three studies that claim $0 \%$ complication rates ${ }^{11-13}$ and one study with a $20 \%$ complication rate. ${ }^{14}$ The authors questioned the utility of these findings citing small sample sizes, short follow up times, multiple surgeons, and multiple approaches as concerns. To address those issues they reported on 341 closed calcaneal fractures treated by the senior author (Bernischke) with ORIF via an extensile lateral approach and a two layer closure. He reported only $1.8 \%$ of his subjects required further intervention. These finding were comparable to the largest study in their literature review which reported three deep infections in 114 fractures for a rate of $2.6 \%{ }^{15}$ Benirschke cited non-compliance as the primary factor of his complications although smoking and predisposing medical conditions also contributed. Other authors have also found smoking, diabetes, and open fractures all increase the risk of wound complication after surgical stabilization of calcaneus fractures. Cumulative risk factors increase the likelihood of wound complications, and consideration should be given to nonsurgical management. ${ }^{16}$

As previously concluded by Pietzrak and Eppley ${ }^{7}$, platelets direct wound healing. They appear almost immediately at the site of soft tissue injury and create a local environment conducive to tissue generation by secretion of proteins from their alpha granules. Basic science supports the hypothesis of enhancing healing by the placement of a supraphysiologic concentration of autologous platelets at the site of soft tissue injury.

So far, PRP has been applied to the following areas of medicine: cardiopulmonary bypass, mandibular bone augmentation for dental implants, diabetic foot ulcers, periodontal, lumbar spine fusion, and cutaneous ulcers, bone grafting, and cardiovascular surgery with documented success. ${ }^{17-24}$ 
Wound complications are the most common and potentially threatening consequence of ORIF of calcaneal fractures. There have been previous papers describing techniques to help lower this complication. Our series matched that of previous studies without a single wound complication. While our series is limited to 14 fractures, several important points can be made. Most series of high energy injuries refer to several factors that can influence complication rates: energy of the injury, surgeon experience, soft tissue handling, medical history, patient compliance, social habits, and nutritional status. It can be said with some certainty that constant experience with calcaneal fractures leads to a decreased complication rate. Although the purpose of this case study is to offer the addition of PRP and PPP to the treatment of these complicated injuries, we believe that our low complication rate is multifactorial. This includes pre-operative bulky Jones type splinting, appropriate surgical timing, preoperative intravenous antibiotic administration, extensile lateral subperiosteal approach, "hands off" retraction, low profile hardware, drain placement, layered closure with Algower-Donati suture technique, surgeon experience and appropriate postoperative bulky splinting.

\section{References}

1. Ruch JA, Taylor GC: Calcaneal Fractures. In Comprehensive Textbook of Foot Surgery $2^{\text {nd }}$ Edition, p1543, edited by ED McGlamry, AS Banks, MS Downey, Williams \& Wilkins, Baltimore, 1992.

2. DiGiovanni CW, Benirschke SK, Hansen ST: Foot Injuries. In Skeletal Trauma $3^{\text {rd }}$ Edition, pp 2406 - 2417, edited by BD Browner, JB Jupiter, AM Levine, PG Trafton. WB Saunders, Philadelphia, 2003.

3. Lance EM, Carey EJ: Fractures of the os calcis: a followup study. J Trauma 4: 15 - 56, 1964.

4. Howard JL, Buckley R, McCormack R, Pate G, Leighton R, Petrie D, Galpin R: Complications following management of displaced intra-articular calcaneal fractures: a prospective randomized trial comparing open reduction internal fixation with nonoperative management. J Orthop Trauma 17(4): 241 249, 2003.

5. Benirschke SK, Kramer PA: Wound healing complications in closed and open calcaneal fractures. J Orthop Trauma 18(1): 1 6, 2004.

6. Sanders R, Fortin P, DiPasquale T, Walling A: Operative treatment in 120 displaced intraarticular calcaneus fractures. Results Using a Prognostic Computed Tomographic Scan Classification. Clin Orthop Rel Res 290: 87 - 95, 1993.
7. Pietrzak WS, Eppley BL: Platelet rich plasma: biology and new technology. J Craniofacial Surgery 16 (6): 1043 - 1054, 2005.

8. Marx RE: Platelet rich plasma (PRP): What is PRP and what is not PRP? Implant Dent 10: 225 - 228, 2001.

9. Borrelli J Jr., Lashgari C: Vascularity of the lateral calcaneal flap: a cadaveric injection study. J Orthop Trauma 13 (2): 73 77, 1999.

10. White RR, Babikian GM: Tibial shaft. In $A O$ principles of fracture management pp 525 - 526, edited by TP Ruedi, WM Murphy, Thieme, New York, 2000.

11. Huang PJ, Huang HT, Chen TB, Chen JC, Lin YK, Cheng YM, Lin SY: Open reduction and internal fixation of displaced intra-articular fractures of the calcaneus. J Trauma 52: 946 - 950: 2002.

12. Raymakers JT, Dekkers GH, Brink PR: Results after operative treatment of intra-articular calcaneal fractures with a minimum follow up of 2 years. Injury 29: 593 - 599, 1998.

13. Stiegelmar R, McKee MD, Waddell JP, Schemitsch EH: Outcome of foot injuries in multiple injured patients. Orthop Clin North Am. 32:193 - 204, 2001.

14. Assous M, Bharma MS: Should os calcis fractures in smokers be fixed? A review of 40 patients. Injury 32: $631-632$, 2001.

15. Naovaratanophas $P$, Thepchatri A: The long term results of internal fixation of displaced intra-articular calcaneal fractures. J Med Assoc Thai 84: 36 - 44, 2001.

16. Early JS, Starr AJ, Folk JW: Early wound complications of operative treatment of calcaneus fractures: analysis of 190 fractures. J Orthop Trauma 13(5): 369 - 372, 1999.

17. Del Rossi AJ, Cernaianu AC, Vertrees RA, Wacker CJ, Fuller ST, Cilley Jr JH, Baldino WA: Platelet-rich plasma reduces postoperative blood loss after cardiopulmonary bypass. J Thorac Cardiovasc Surg 100: 281 - 286, 1990.

18. Marx RE: Platelet concentrate: a strategy for accelerating and improving bone regeneration. In Bone Engineering, pp $447-$ 453, edited by JE Davies, University of Toronto, Toronto, 2000. 19. Margolis DJ, Kantor J, Santanna J: Effectiveness of platelet releasate for the treatment of diabetic neuropathic foot ulcers. Diabetes Care 24 (3): 483 - 488, 2001.

20. Anitua E: Plasma rich in growth factors: preliminary results of use in the preparation of future sites for implants. J Oral Implantol 14: 529 - 535, 1999.

21. Hee HT, Majd ME, Holt RT, Myers L: Do autologous growth factors enhance transforaminal lumbar interbody fusion? Eur Spine J 12: 400 - 407, 2003.

22. Knighton DR, Ciresi K, Fiegel VD, Schumerth S, Butler E, Cerra F: Stimulation of repair in chronic, nonhealing, cutaneous ulcers using platelet-derived wound healing formula. Surg Gynecol Obstet 170: 56 - 60, 1990.

23. Marx RE, Carlson ER, Eichstaedt RM, Schimmele SR, Strauss JE, Georgeff KR: Platelet-rich plasma. Growth factor for enhancement for bone grafts. Oral Surg Oral Med Oral Pathol Oral Radiol Endod 85: 638 - 646, 1998.

24. Englert SJ, Estep TH, Ellis-Stoll CC: Autologous Platelet Gel Applications During Cardiovascular Surgery: Effect on Wound Healing. JECT 37: 148 - 152, 2005. 